\title{
Efficacy and safety of cinacalcet compared with other treatments for secondary hyperparathyroidism in patients with chronic kidney disease or end-stage renal disease: a meta-analysis
}

\author{
Yiting Sun', Binyao Tian², Zitong Sheng ${ }^{2}$, Pengzhi Wan², Tianhua X $\mathrm{u}^{2}$ and Li Yao ${ }^{2 *}$
}

\begin{abstract}
Background: It is controversial for the effect and safety between cinacalcet and other treatments in treating secondary hyperparathyroidism for patients with chronic kidney disease (CKD) or end-stage renal disease (ESRD).

Methods: Embase, PubMed, and Cochrane Library were searched through Feb 2017. 21 randomized controlled trials were included. We calculated the pooled mean difference (MD), relative risk (RR) and corresponding 95\% confidence interval (CI).

Result: Patients received calcimimetic agents had significantly decreased serum parathyroid hormone (MD =$259.24 \mathrm{pg} / \mathrm{mL}, 95 \% \mathrm{Cl}:-336.23$ to -182.25$)$, calcium (MD $=-0.92 \mathrm{mg} / \mathrm{dL}, 95 \% \mathrm{Cl}:-0.98$ to -0.85$)$ and calcium phosphorus product ( $\mathrm{MD}=-5.97 \mathrm{mg}^{2} / \mathrm{dL}^{2}, 95 \% \mathrm{Cl}$ : 9.77 to -2.16 ) concentration compared with control treatment. However, the differences in cardiovascular mortality and all-cause mortality between calcimimetics agents and control group were not statistically significant. The incidence of nausea (RR $=2.13,95 \%$ Cl: 1.62 to 2.79 ), vomiting ( $R R=1.99,95 \%$ Cl: 1.78 to 2.23 ) and hypocalcemia ( $R R=10.10,95 \%$ Cl: 7.60 to 13.43) in CKD patients with calcimimetics agents was significantly higher than that with control treatment.
\end{abstract}

Conclusion: Cinacalcet improved the biochemical parameters in CKD patients, but did not improve all-cause mortality and cardiovascular mortality. Moreover, cinacalcet can cause some adverse events.

Keywords: Cinacalcet, Chronic kidney disease, End-stage renal disease, Meta-analysis, Secondary hyperparathyroidism

\section{Background}

Cardiovascular $(\mathrm{CV})$ events in patients with chronic kidney disease (CKD) occur frequently [1]. CKD patient population experiences a high burden of cardiovascular mortality etyjhigher than general population. There are many causes of $\mathrm{CV}$ disease in chronic kidney disease, but mineral and bone disorder (MBD), including hyperphosphatemia, secondary hyperparathyroidism (SHPT) and vascular calcification. SHPT frequently occurs in

\footnotetext{
*Correspondence: liyao_cmu@163.com

${ }^{2}$ Department of Nephrology, the First Hospital of China Medical University,

Shenyang 110001, Liaoning, China

Full list of author information is available at the end of the article
}

patients with chronic renal failure. It is well developed before patients enters ESRD and as hemodialysis progresses, the patient's parathyroid hormone (PTH) levels gradually increase. Traditional SHPT therapies generally includes Vitamin D sterols and phosphate binders. Although Vitamin D sterols can be effective in reducing serum intact PTH (iPTH) levels, it also increases serum levels of calcium and phosphorus, but also leading to hypercalcemia and an elevated serum calcium-phosphorus product $[2,3]$. Percutaneous ethanol injection and parathyroidectomy therapies, have potential complications including throat necrosis, laryngeal recurrent nerve injury lead to weakness or paralysis of vocal cord, impaired 
healing, prolonged pain, and other issues related to surgical intervention.

Cinacalcet, an orally administered calcimimetic agent was originally approved in 2004 for the treatment of SHPT in patients with ESRD [4]. Cinacalcet acts by increasing the sensitivity of the calcium-sensing receptor (CaSR) on parathyroid cells to extracellular calcium ion levels, thereby decreasing serum PTH without increasing serum calcium, phosphate or the calcium phosphate product $(\mathrm{Ca} \times \mathrm{P})$ in SHPT patients $[4,5]$. In addition, cinacalcet lowers serum fibroblast growth factor-23 (FGF23) levels in haemodialysis patients.

The difference of effective and safety of cinacalcet in treatment of secondary hyperparathyroidism in patients with CKD or ESRD with other treatments is controversial [4, 6-25]. Therefore, we performed a meta-analysis and systematic review to quantitatively assess this relationship.

\section{Methods}

\section{Search strategy}

The PubMed, Cochrane Library and Embase databases were searched using the following key terms: ("cinacalcet") AND ("chronic kidney disease/CKD" OR "endstage renal disease/ESRD") (last updated in Feb. 2017). Moreover, references in relevant articles were also manually cross-searched for additional trials.

\section{Selection criteria}

The findings are reported according to the Preferred Reporting Items for Systematic Reviews and MetaAnalyses (PRISMA) [26]. All studies had to meet the following inclusion criteria: (a) study design had to be a RCT based on human subjects; (b) interventions had to be calcimimetic agents vs. control treatment; and (c) studies should report at least one of the outcomes with serum PTH, calcium, phosphate, calcium phosphorus product, all-cause mortality, nausea, vomiting, cardiovascular mortality, hypercalcemia and hypocalcemia. The following exclusion criteria were used: (a) abstracts or overlapped studies; and (b) studies published in languages other than English; (c) studies in animal models.

\section{Data extraction and quality assessment}

All the available data on outcomes were independently extracted by two investigators from each study based on the inclusion criteria listed above. Any disagreement was resolved by discussing with the third expert. The study characteristics were recorded as follows: first author name, publication year, country where the research was performed, number of patients, mean age, intervention method, duration of the trial, serum PTH, calcium, phosphate, calcium phosphorus product, all-cause mortality, nausea, vomiting, cardiovascular mortality, hypercalcemia and hypocalcemia. We evaluate the quality of
RCTs with the Cochrane Collaboration's tool for assessing risk of bias [27]. The assessment will include the following components: random sequence generation, blinding of patients and study personnel, allocation concealment, blinding of outcome assessment, selective reporting of outcomes, completeness of outcome data, and other threats. The following response options were included: "probably yes", "definitely yes", "definitely no", and "probably no", with "probably yes" or "definitely yes" assigned low risk of bias and "probably no" or "definitely no" assigned high risk of bias.

\section{Statistical analysis}

All results summarized using STATA Software (version 12, Stata Corporation, College Station, TX). For the continuous data, we calculated the mean difference (MD) and $95 \%$ confidence intervals (CI). For dichotomous data, the risk ratio (RR) and 95\% confidence intervals were calculated. Between-study heterogeneity was examined using $X^{2}$ test and $I^{2}$, which assumes the presence of heterogeneity at $I^{2}>50 \%$. Preliminary analysis using a fixed effect model (Mantel-Haenszel method), if there are study heterogeneity $\left(P<0.1\right.$ and/or $\left.I^{2}>50 \%\right)$, using a random effects model. In the sensitivity analysis, the influence of each study on the summary effect was analyzed by dropping one study at a time. By funnel plot, Begg's and Egger's test to assess publication bias visually evaluated symmetry $(P<0.05$ was considered statistically significant).

\section{Results}

\section{Characteristics of the studies}

As is demonstrated in Fig. 1, a total of 309 articles were identified, 273 of which were determined to be irrelevant based on review of titles and abstracts. Thus, a total of 36 full-text articles were assessed for eligibility. Of these 36 articles, 15 were excluded because them didn't meet the inclusion criteria, including eight not focusing on cinacalcet, three without control, four not present the usable data. In total, 21 articles fulfilled the inclusion criteria and were enrolled. Of the 21 retrieved articles, 8373 participants are represented. In total, the 21 RCTs represented 4543 and 3830 patients in the calcimimetic agents and control treatment groups, respectively. The characteristics of the retrieved trials and the recorded outcomes are reported in Table 1 . The treatment duration ranged from 2 to 52 weeks. A summary of selection bias, detection bias, performance bias, reporting bias, attrition bias, and other bias identified in each individual RCT is shown in Fig. 2. All of the included studies showed moderate and high quality with acceptable and moderate risk of bias. 


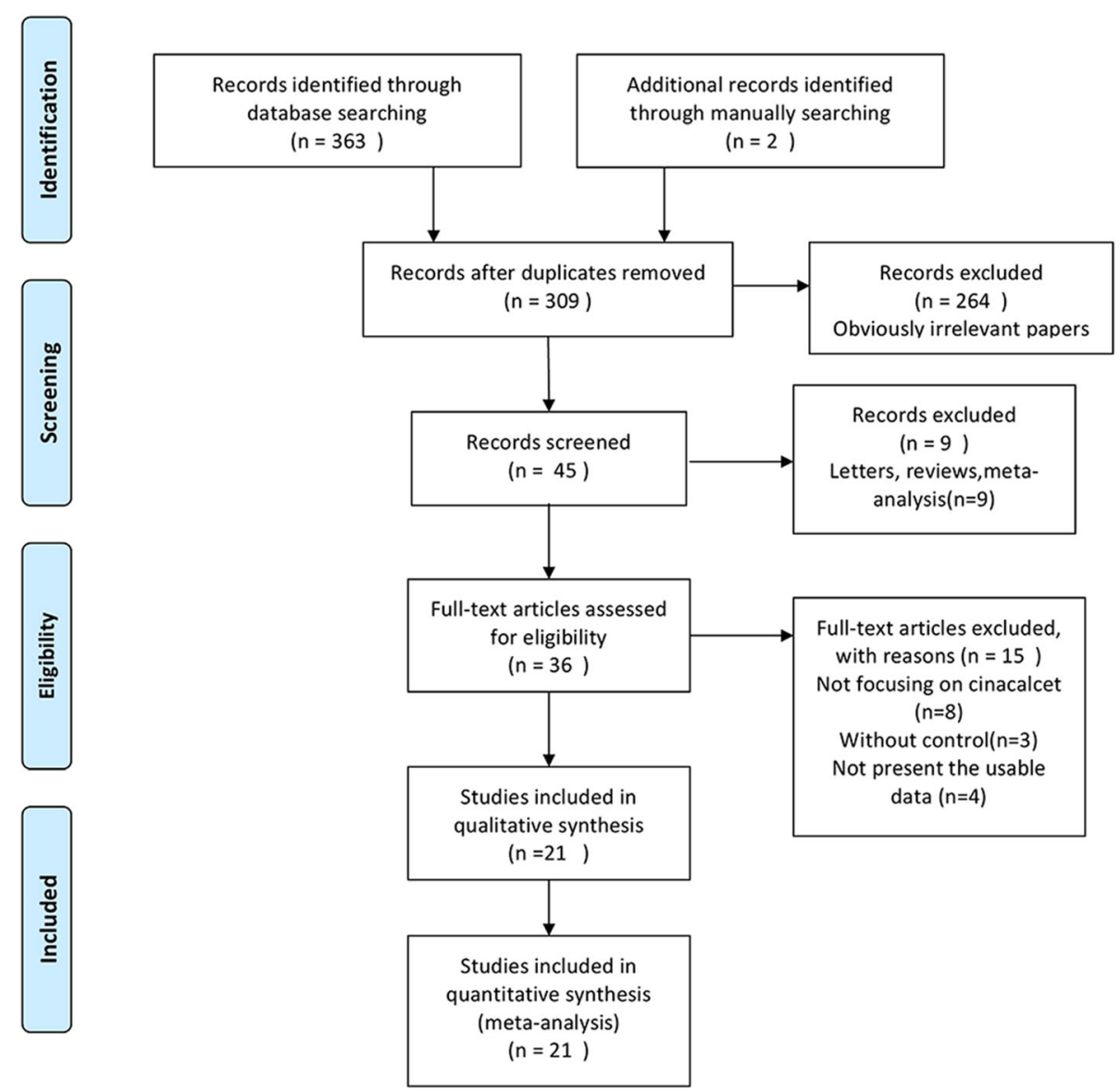

Fig. 1 Flow diagram of studies identification

\section{Quantitative synthesis}

The eight studies $[4,8,9,11,15,17,24,25]$ provided numerical data regarding the serum PTH concentration in patients who received calcimimetic agents and control treatment, and were included in the meta-analysis. There was evidence of heterogeneity among the 8 studies, therefore, a random-effects model of analysis was used. The pooled difference in means indicated that patients who received calcimimetic agents $(\mathrm{MD}=-259.24 \mathrm{pg} / \mathrm{mL}, 95 \%$ CI: -336.23 to $\left.-182.25, P_{\text {heterogeneity }}<0.001, I^{2}=79.6 \%\right)$ had significantly decreased serum PTH concentration compared with patients who received control treatment (Fig.3a). We probed into detailed results in subgroup analyses stratified by country (USA or other country), patient median age (patient median age $<55$ or $\geq 55$ ), sample size (sample size $<200$ or $\geq 200$ ), dialysis or not and duration of the trial (duration of the trial $<24 \mathrm{w}$ or $\geq 24 \mathrm{w}$ ). All subgroup results were quite consistent with the overall results. The results are summarized in Table 2 .

The eight studies $[9,11,14-17,24,25]$ provided numerical data regarding the serum calcium concentration in patients who received calcimimetic agents and control treatment, and were included in the meta-analysis. There was no evidence of heterogeneity among the 8 studies, therefore, a fixed-effects model of analysis was used. The pooled difference in means indicated that patients who received calcimimetic agents $(\mathrm{MD}=-0.92 \mathrm{mg} / \mathrm{dL}, 95 \% \mathrm{CI}:-$ 0.98 to $\left.-0.85, P_{\text {heterogeneity }}=0.124, I^{2}=38.3 \%\right)$ had significantly decreased serum calcium concentration compared with patients who received control treatment (Fig. 3b).

The nine studies [4, 9, 11, 14-17, 24, 25] provided numerical data regarding the serum phosphate concentration in patients who received calcimimetic agents and control treatment, and were included in the meta-analysis. There was evidence of heterogeneity among the 9 studies, therefore, a random-effects model of analysis was used. The pooled difference in means indicated that patients who received calcimimetic agents $(\mathrm{MD}=-0.31 \mathrm{mg} / \mathrm{dL}, 95 \% \mathrm{CI}$ :0.63 to $0.01, P_{\text {heterogeneity }}<0.001, I^{2}=88.7 \%$ ) had not significantly decreased serum phosphate concentration compared with patients who received control treatment (Fig. 3c). We probed into detailed results in subgroup analyses stratified by country, patient median age, sample size, and duration of the trial. All subgroup results are summarized in Table 2. 


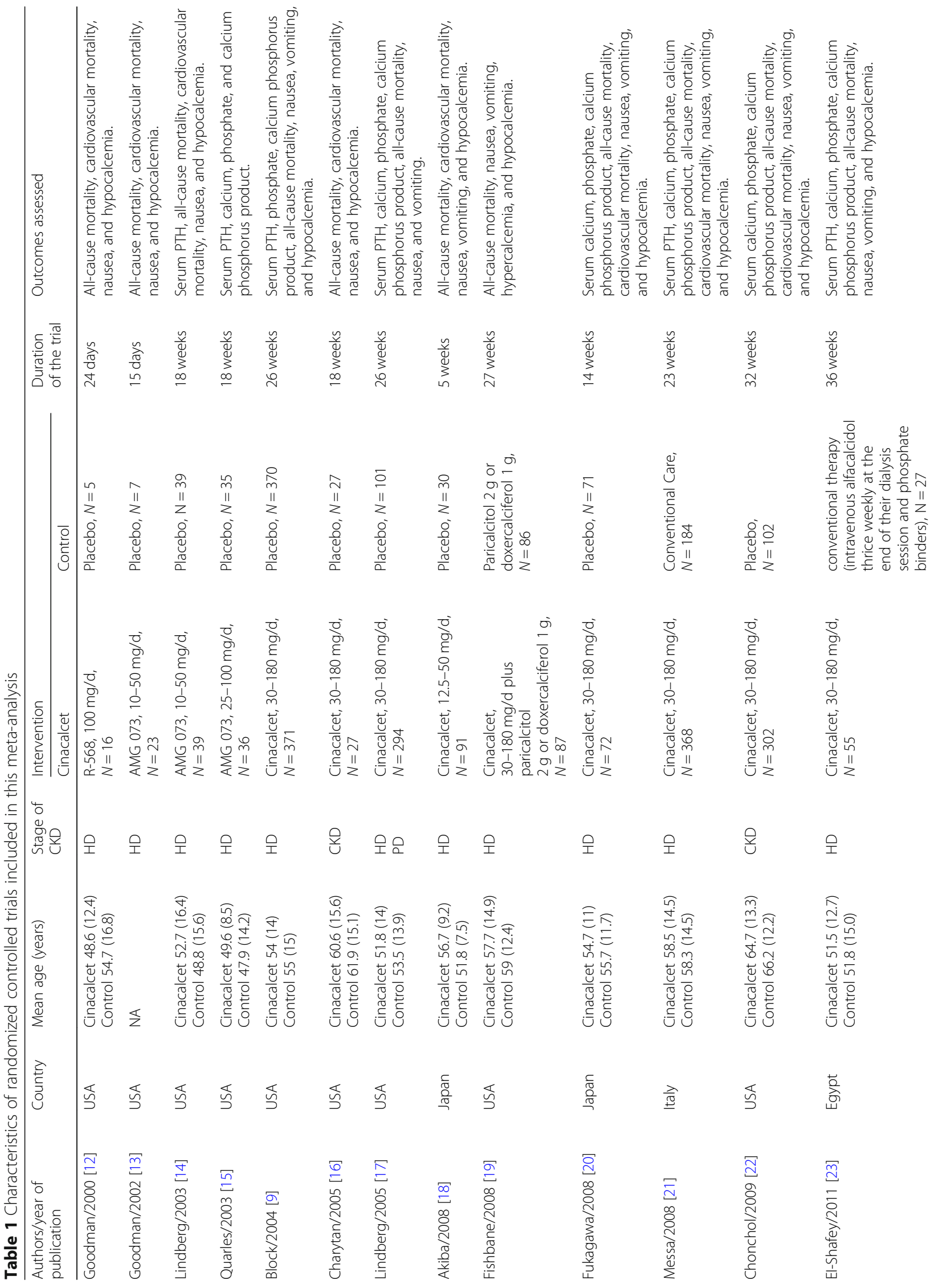


Sun et al. BMC Nephrology

(2020) 21:316

Page 5 of 12

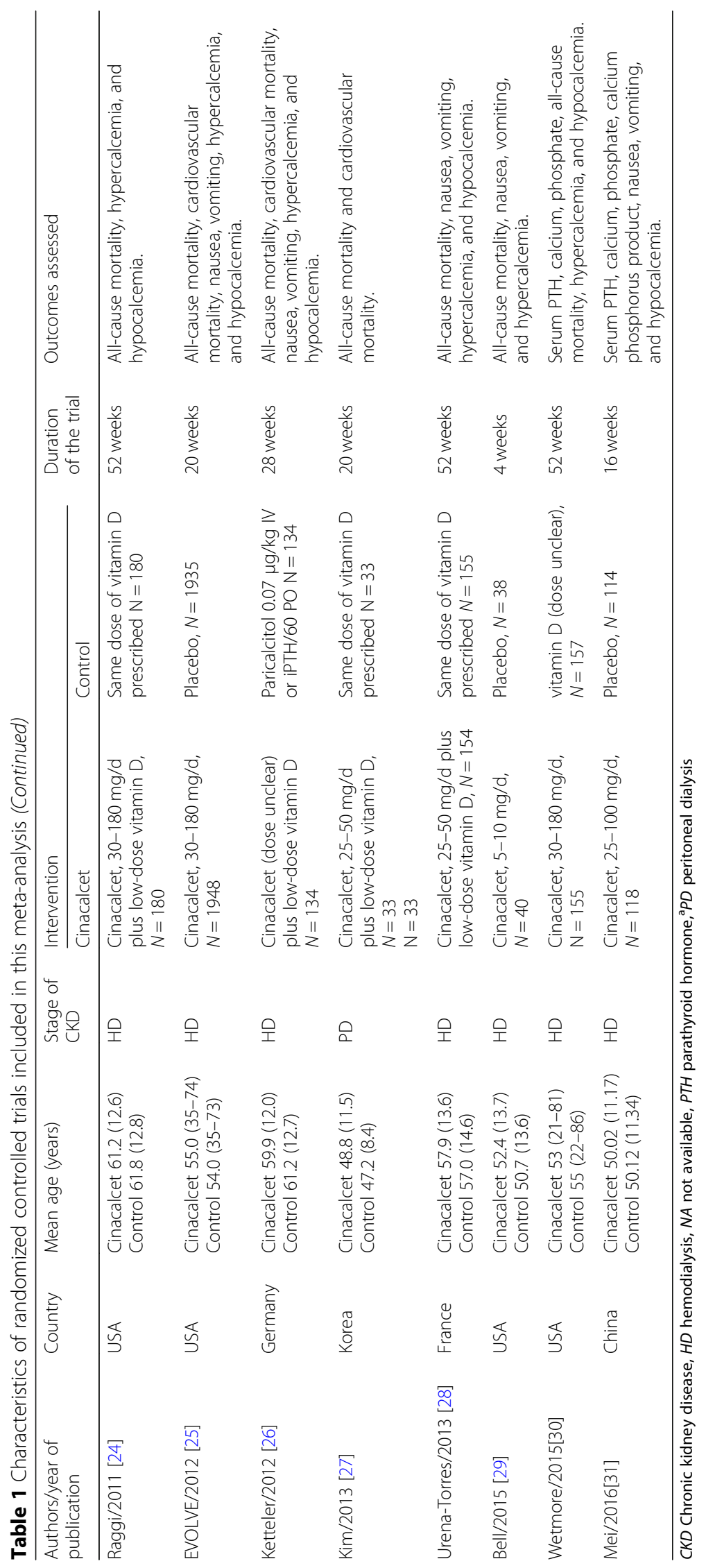




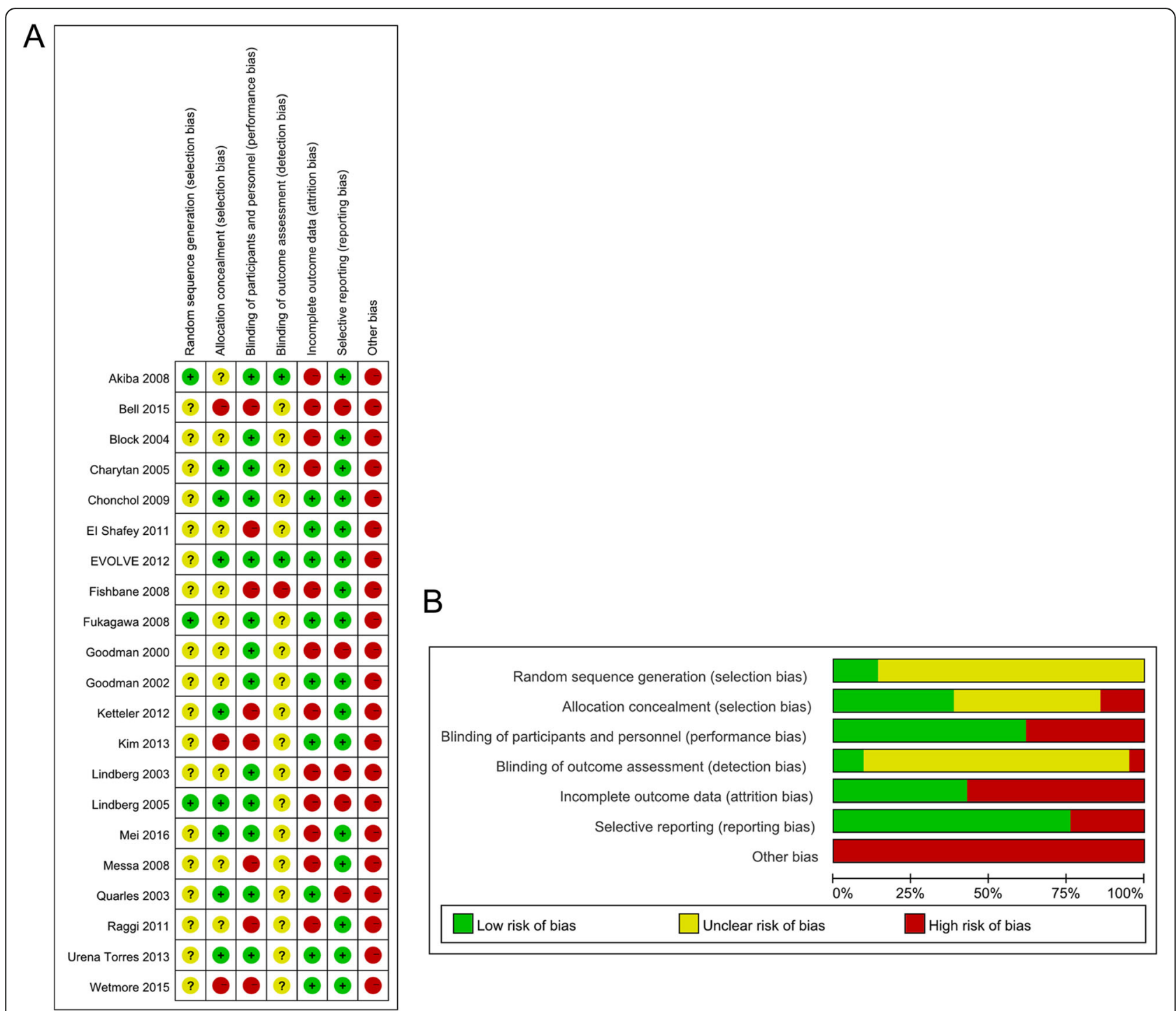

Fig. 2 Risk of bias assessments for the randomized trials included in the meta-analysis. A) Risk of bias summary; B) Risk of bias graph. Symbols. (+): low risk of bias; (?): unclear risk of bias; (-): high risk of bias

The eight studies $[4,9,11,14-17,24,25]$ provided numerical data regarding the serum calcium phosphorus product in patients who received calcimimetic agents and control treatment, and were included in the metaanalysis. There was evidence of heterogeneity among the 8 studies, therefore, a random-effects model of analysis was used. The pooled difference in means indicated that patients who received calcimimetic agents $(\mathrm{MD}=-5.97$ $\mathrm{mg}^{2} / \mathrm{dL}^{2}, 95 \% \mathrm{CI}:-9.77$ to $-2.16, P_{\text {heterogeneity }}<0.001$, $\left.I^{2}=91.1 \%\right)$ had significantly decreased serum calcium phosphorus product compared with patients who received control treatment (Fig. 3d). We probed into detailed results in subgroup analyses stratified by country, patient median age, sample size, and duration of the trial. All subgroup results are summarized in Table 2 .

\section{All-cause mortality (ACM)}

This outcome was reported in 19 trials. There was no significant heterogeneity between the study $(P=0.859$, $\left.I^{2}=0 \%\right)$, the fixed effect model was used. There was no significant difference in the incidence of ACM in patients received calcimimetic agents compared with control treatment group ( $\mathrm{RR}=0.97,95 \% \mathrm{CI}$ : 0.89 to 1.05$)$, as shown in Fig. 4a.

\section{Cardiovascular mortality (CVM)}

This outcome was reported in eleven trials. There was no significant heterogeneity between the study $(P=$ $0.434, I^{2}=0 \%$ ), the fixed effect model was used. There was no significant difference in the incidence of CVM $(\mathrm{RR}=0.94,95 \%$ CI: 0.83 to 1.07), as shown in Fig. 4b. 


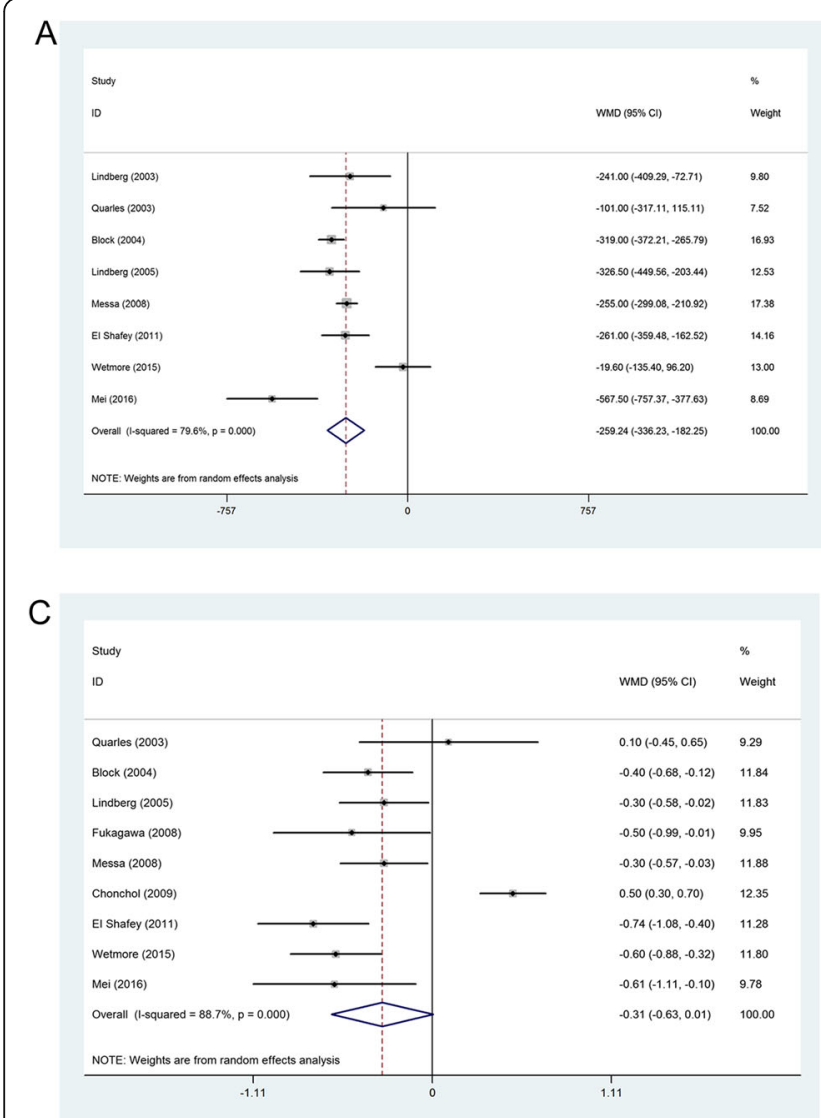

B

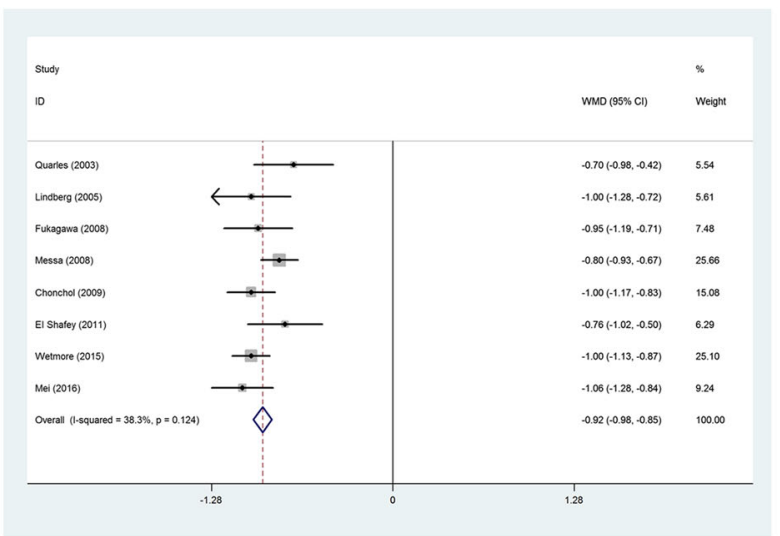

D

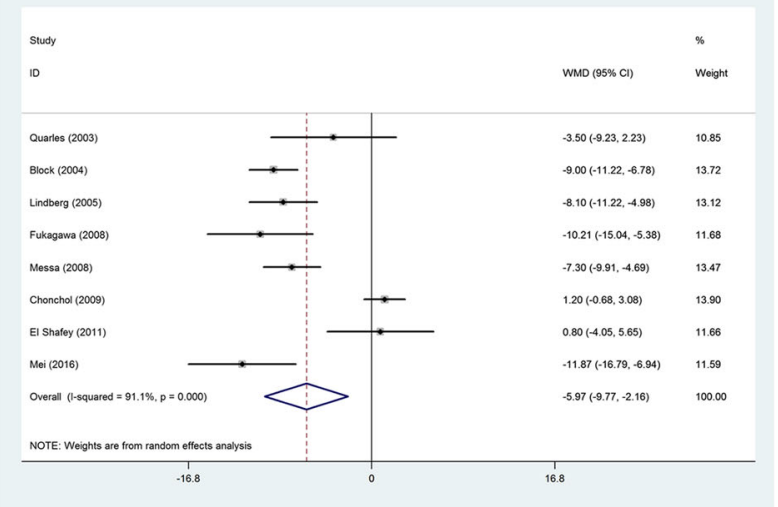

Fig. 3 Effect of cinacalcet versus control treatment in patients with chronic kidney disease. A) Serum parathyroid hormone; B) Serum calcium; C) Serum phosphate; D) Calcium phosphorus product

The nineteen studies $[4,6-8,10-17]$ were included in the meta-analysis of adverse events.

\section{Nausea}

This outcome was reported in 17 trials. There was significant heterogeneity between the study $\left(P=0.001, I^{2}=59.2 \%\right)$, the random effect model was used. There was significantly increased the incidence of nausea in patients received calcimimetic agents compared with control treatment group $(\mathrm{RR}=$ 2.13, 95\% CI: 1.62 2.79), as shown in Fig. 5a.

\section{Vomiting}

This outcome was reported in 13 trials. There was no significant heterogeneity between the study $\left(P=0.579, I^{2}=0 \%\right)$, the fixed effect model was used. There was significantly increased the incidence of vomiting in patients received calcimimetic agents compared with control treatment group $(\mathrm{RR}=1.99,95 \% \mathrm{CI}: 1.78$ to 2.23$)$, as shown in Fig. $5 \mathrm{~b}$.

\section{Hypercalcemia}

This outcome was reported in seven trials. There was significant heterogeneity between the study $(P<0.001$, $\left.I^{2}=83.2 \%\right)$, the random effect model was used. There was significantly decreased the incidence of hypercalcemia in patients received calcimimetic agents compared with control treatment group ( $\mathrm{RR}=0.28,95 \% \mathrm{CI}$ : 0.08 to 0.94), as shown in Fig. 5c.

\section{Hypocalcemia}

This outcome was reported in 17 trials. There was no significant heterogeneity between the studies $\left(P=0.389, I^{2}=5.6 \%\right)$, the fixed effect model was used. There was significantly increased the incidence of hypocalcemia in patients received calcimimetic agents compared with control treatment group $(\mathrm{RR}=10.10,95 \%$ CI: 7.60 to 13.43$)$, as shown in Fig. S1D.

\section{Sensitivity analysis}

We performed sensitivity analyses to assess the stability of the results by sequential removing each study. Any single study was removed, while the overall statistical results do not change, indicating that the results of this study are statistically robust.

\section{Publication bias}

Egger's, Begg's test and funnel plot were performed to evaluate publication bias of the literatures. Funnel 
Table 2 Subgroup analysis of the meta-analysis

\begin{tabular}{|c|c|c|c|c|c|}
\hline Outcomes & Subgroup & $\begin{array}{l}\text { Number of } \\
\text { trials }\end{array}$ & Effect $(95 \% \mathrm{Cl})$ & $\begin{array}{l}\text { Estimate for overall } \\
\text { effect }\end{array}$ & Heterogeneity \\
\hline \multirow[t]{8}{*}{ Serum PTH concentration } & USA & 5 & $-209.57(-341.06,-78.07)$ & $P=0.002$ & $P=83.6 \%, P<0.001$ \\
\hline & Other country & 3 & $-327.13(-454.5,-199.77)$ & $P<0.001$ & $P^{2}=79.8 \%, P=0.007$ \\
\hline & $\begin{array}{l}\text { Patient median age } \\
<55\end{array}$ & 5 & $-300.73(-417.8,-183.67)$ & $P<0.001$ & $P^{2}=67 \%, P=0.017$ \\
\hline & $\begin{array}{l}\text { Patient median age } \\
\geq 55\end{array}$ & 3 & $-211.64(-330.57,-92.72)$ & $P<0.001$ & $P=90.6 \%, P<0.001$ \\
\hline & Sample size $<200$ & 3 & $-235.15(-314.24,-156.05)$ & $P<0.001$ & $P^{2}=0, P=0.417$ \\
\hline & Sample size $\geq 200$ & 5 & $-281.23(-385.59,-176.88)$ & $P<0.001$ & $P^{2}=87.5 \%, P<0.001$ \\
\hline & $\begin{array}{l}\text { Duration of the trial } \\
<24 w\end{array}$ & 4 & $-289.97(-435.79,-144.15)$ & $P<0.001$ & $P^{2}=75.5 \%, P=0.007$ \\
\hline & $\begin{array}{l}\text { Duration of the trial } \\
\geq 24 \mathrm{w}\end{array}$ & 4 & $-235.23(-361.52,-108.95)$ & $P<0.001$ & $P^{2}=86.4 \%, P<0.001$ \\
\hline \multirow[t]{10}{*}{ Serum phosphate concentration } & USA & 5 & $-0.14(-0.61,0.32)$ & $P=0.544$ & $P=92.3 \%, P<0.001$ \\
\hline & Other country & 4 & $-0.51(-0.73,-0.29)$ & $P<0.001$ & $P^{2}=27.1 \%, P=0.249$ \\
\hline & $\begin{array}{l}\text { Patient median age } \\
<55\end{array}$ & 4 & $-0.41(-0.74,-0.09)$ & $P=0.013$ & $P^{2}=62.2 \%, P=0.047$ \\
\hline & $\begin{array}{l}\text { Patient median age } \\
\geq 55\end{array}$ & 5 & $-0.25(-0.71,0.22)$ & $P=0.297$ & $P^{2}=92.7 \%, P<0.001$ \\
\hline & Sample size $<200$ & 3 & $-0.42(-0.89,0.05)$ & $P=0.081$ & $P^{2}=68.6 \%, P=0.042$ \\
\hline & Sample size $\geq 200$ & 6 & $-0.27(-0.66,0.12)$ & $P=0.175$ & $P^{2}=91.3 \%, P<0.001$ \\
\hline & $\begin{array}{l}\text { Duration of the trial } \\
<24 w\end{array}$ & 4 & $-0.33(-0.58,-0.09)$ & $P=0.008$ & $P^{2}=24.9 \%, P=0.262$ \\
\hline & $\begin{array}{l}\text { Duration of the trial } \\
\geq 24 \mathrm{~W}\end{array}$ & 5 & $-0.30(-0.79,0.19)$ & $P=0.226$ & $P^{2}=93.8 \%, P<0.001$ \\
\hline & Receiving dialysis & 8 & $-0.43(-0.58,0.29)$ & $P<0.001$ & $R^{2}=32.3 \%, P=0.170$ \\
\hline & $\begin{array}{l}\text { Not receiving } \\
\text { dialysis }\end{array}$ & 1 & $0.50(0.3,0.7)$ & $P<0.001$ & - \\
\hline \multirow{10}{*}{$\begin{array}{l}\text { Serum calcium phosphorus } \\
\text { product }\end{array}$} & USA & 4 & $-4.86(-10.82,1.09)$ & $P=0.109$ & $P^{2}=94.6 \%, P<0.001$ \\
\hline & Other country & 4 & $-7.15(-11.88,-2.41)$ & $P=0.003$ & $R^{2}=80.5 \%, P=0.002$ \\
\hline & $\begin{array}{l}\text { Patient median age } \\
<55\end{array}$ & 4 & $-5.79(-10.91,-0.66)$ & $P=0.027$ & $P^{2}=80.4 \%, P=0.002$ \\
\hline & $\begin{array}{l}\text { Patient median age } \\
\geq 55\end{array}$ & 4 & $-6.18(-11.98,-0.37)$ & $P=0.037$ & $P^{2}=95.1 \%, P<0.001$ \\
\hline & Sample size <200 & 3 & $-4.33(-10.96,2.31)$ & $P=0.201$ & $P^{2}=80.1 \%, P=0.007$ \\
\hline & Sample size $\geq 200$ & 5 & $-6.84(-11.77,-1.91)$ & $P=0.007$ & $R^{2}=94.2 \%, P<0.001$ \\
\hline & $\begin{array}{l}\text { duration of the trial } \\
<24 w\end{array}$ & 4 & $-8.26(-11.28,-5.24)$ & $P<0.001$ & $P^{2}=48.4 \%, P=0.121$ \\
\hline & $\begin{array}{l}\text { duration of the trial } \\
\geq 24 \mathrm{w}\end{array}$ & 4 & $-3.87(-9.85,2.12)$ & $P=0.206$ & $R^{2}=94.9 \%, P<0.001$ \\
\hline & Receiving dialysis & 7 & $-7.29(-9.77,-4.81)$ & $P<0.001$ & $P^{2}=68.6 \%, P=0.004$ \\
\hline & $\begin{array}{l}\text { Not receiving } \\
\text { dialysis }\end{array}$ & 1 & $1.20(-0.68,3.08)$ & $P=0.210$ & - \\
\hline
\end{tabular}

CKD Chronic kidney disease, HD hemodialysis, NA not available, $P T H$ parathyroid hormone, $P D$ peritoneal dialysis

plots revealed no evidence of publication bias for incidence of vomiting (Begg's test $P=0.428$; Egger's test $P=0.063$ ) (Fig. 6a) and incidence of hypocalcemia (Begg's test $P=0.592$; Egger's test $P=0.251$ ) (Fig. 6b).

\section{Discussion}

A comprehensive search was conducted, and finally 21 randomized clinical trials involving 8373 CKD patients met our inclusion criteria. Our study showed that patients who received calcimimetic agents had significantly 

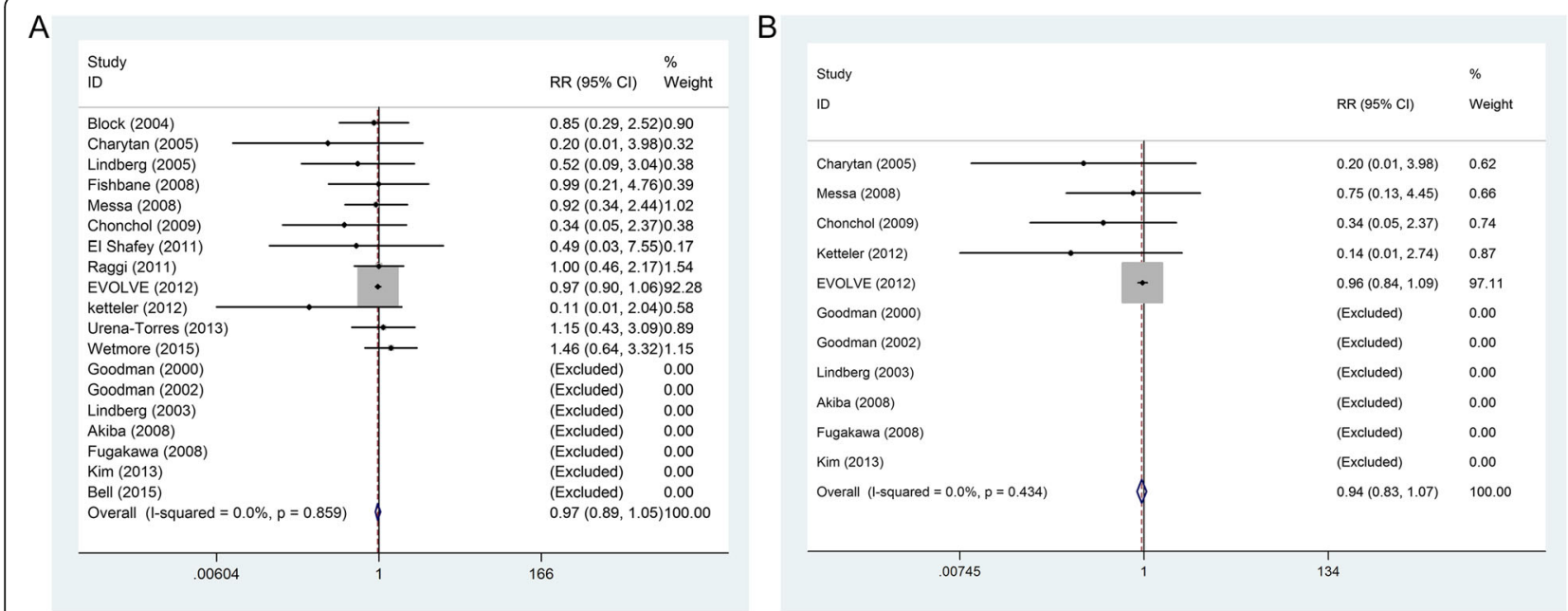

Fig. 4 Forest plot of mortality with cinacalcet versus control treatment in patients with chronic kidney disease. A) All-cause mortality; B) Cardiovascular mortality
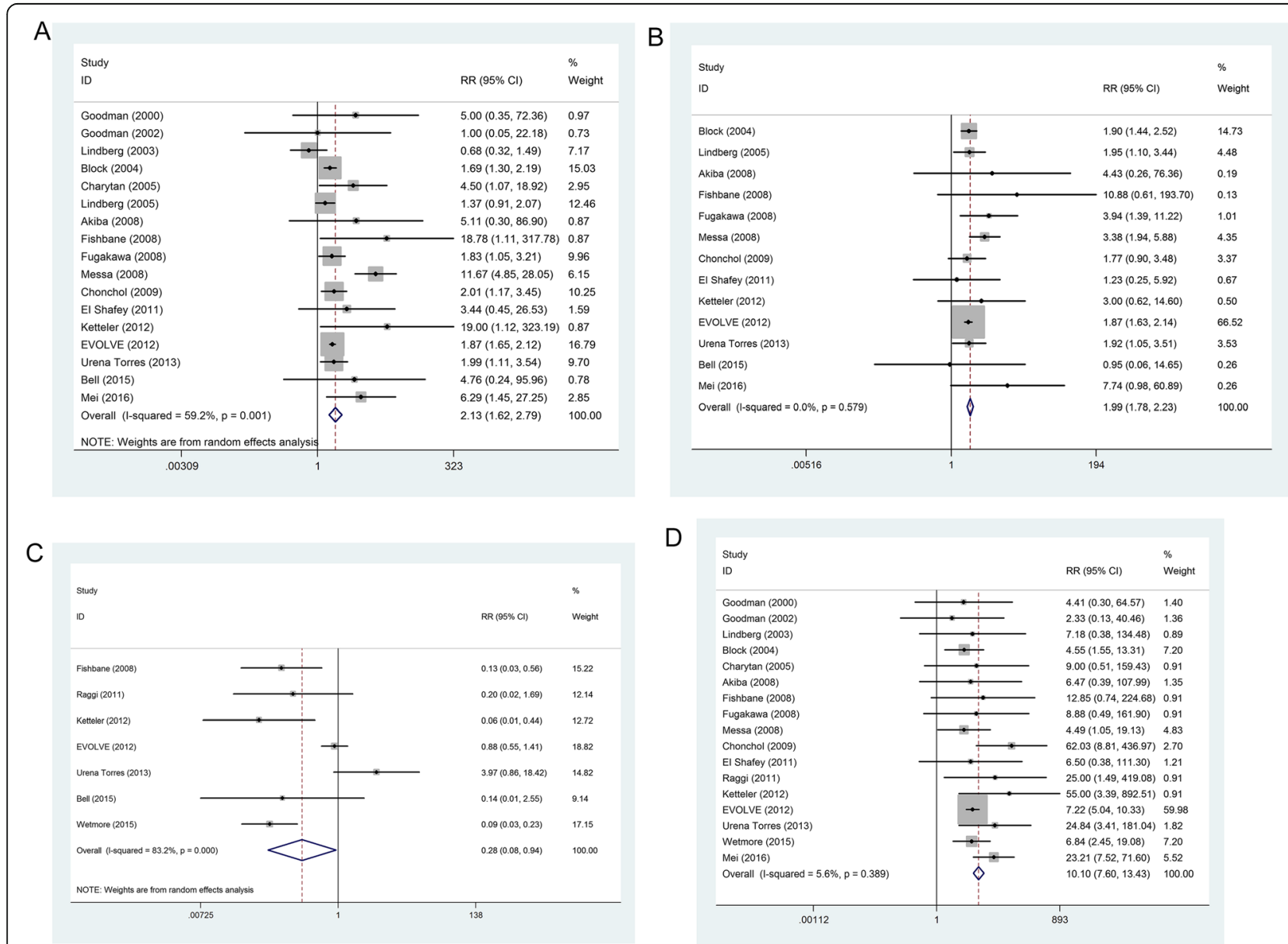

Fig. 5 Pooled risk ratio of adverse events with cinacalcet versus control treatment in patients with chronic kidney disease. A) Nausea; B) Vomiting; C) Hypercalcemia; D) Hypocalcemia 


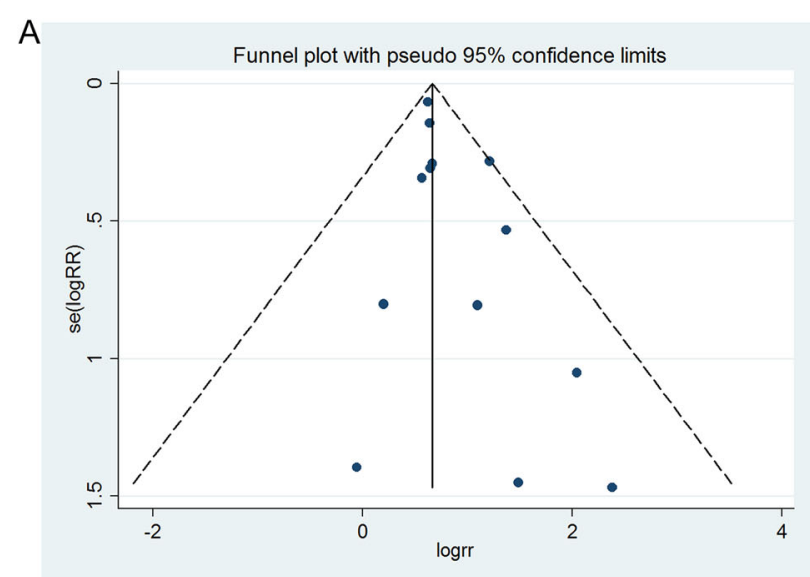

B

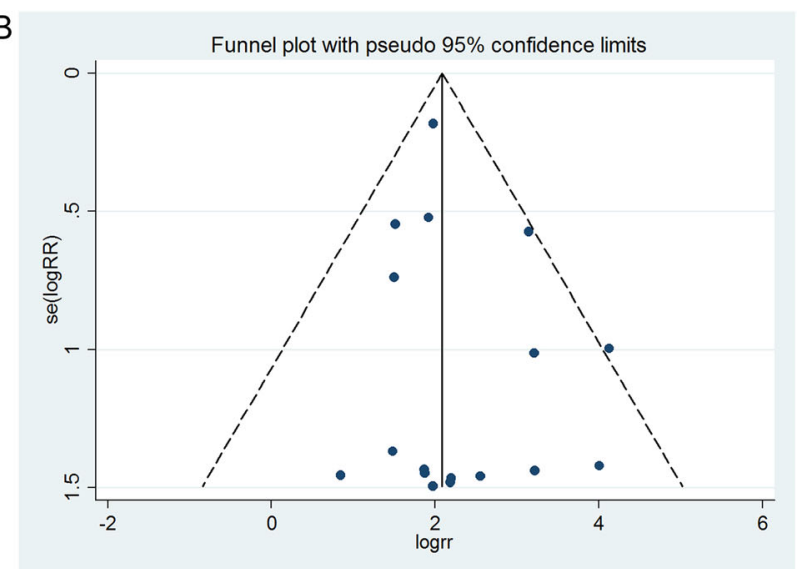

Fig. 6 Funnel plot for publication bias test. Each point represents a separate study for the indicated association. (A) Incidence of vomiting; and (B) incidence of hypocalcemia

decreased serum PTH $(\mathrm{MD}=-259.24 \mathrm{pg} / \mathrm{mL}, 95 \% \mathrm{CI}$ : 336.23 to $-182.25, \quad P_{\text {heterogeneity }}<0.001, \quad I^{2}=79.6 \%$ ), calcium $(\mathrm{MD}=-0.92 \mathrm{mg} / \mathrm{dL}, 95 \% \mathrm{CI}:-0.98$ to -0.85 , $\left.P_{\text {heterogeneity }}=0.124, I^{2}=38.3 \%\right)$ and calcium phosphorus product $\left(\mathrm{MD}=-5.97 \mathrm{mg}^{2} / \mathrm{dL}^{2}, 95 \% \mathrm{CI}:-9.77\right.$ to -2.16 , $\left.P_{\text {heterogeneity }}<0.001, I^{2}=91.1 \%\right)$ concentration compared with patients who received control treatment. However, there was no significant difference in cardiovascular mortality and all-cause mortality between calcimimetics agents and control treatment group. Furthermore, we observed that the incidence of adverse events (nausea, vomiting and hypocalcemia) in CKD patients treated with calcimimetics agents was significantly higher than that with control treatment.

The efficacy and safety of calcimimetic agents have been investigated by several meta-analyses. As far as we know, this meta-analysis is the largest one to evaluate the efficacy and safety profile of calcimimetic agents up to now, which involved 8373 CKD patients from 21 RCTs. Recently, Palmer et al. [28] performed a meta-analysis about the efficacy and safety of cinacalcet in CKD patients. Compared with Palmer's work, we identified more eligible studies. Compared with another meta-analysis about calcimimetic agents reported by Sekercioglu et al. [29], we included more new RCTs, involved more CKD patients and performed a detailed analysis. Vascular calcification is a very common and serious problem in adult ESRD patients and is significantly associated with cardiovascular disease and mortality. In this study, there was no evidence of a reduction in cardiovascular mortality and all-cause mortality in cinacalcet compared with the control. These results are consistent with previous findings. Heterogeneity is a problem with most meta-analyses. In this meta-analysis, heterogeneity was found in the subgroup and overall analyses; thus, we used the random-effects model. Based on the data collected, we suggested that the sample size and duration of the trial have at least partly contributed to the betweenstudy heterogeneity. However, clinical heterogeneity may or may not produce detectable statistical heterogeneity. Important clinical differences between studies, for example, between patient populations, intervention protocols and the types and timing of study outcomes - can be present in the absence of statistical heterogeneity. These differences can limit the appropriateness of statistical synthesis of individual study estimates through meta-analysis. Furthermore, we performed sensitivity analyses to assess the stability of the results by sequential removing each study. Any single study was removed, while the overall statistical results do not change, indicating that the results of this study are statistically robust.

SHPT and MBD are common in many patients with CKD. Due to increased risk of CVD, occurrence of fractures and mortality, two clinical conditions bring a large amount medical burden. Management of SHPT and MBD in patients with CKD is made by controlling the triggering factors. Sometimes these measures are not effective, and maybe even have adverse effects. As the main physiological factors of the two entities, the calcium agent provides a therapeutic advantage. Firstly, they reduce the level of serum PTH by inhibiting their secretion, and secondly, they stimulate the synthesis of the vitamin D receptor in the parathyroid gland, which increases the sensitivity to vitamin D and subsequently inhibits PTH. At present, focus has moved to the effect of cinacalcet on hard clinical end point, and ADVANCE [18] and EVOLVE [19], two randomized controlled trials, have been performed to assess the impact of cinacalcet on CV calcification and the risk of CV events and mortality. Although the initial analysis of the two trials did not reveal significant effects of cinacalcet, the advantage of cinacalcet was proposed to analyze the potential problems considered in the test. These positive results and experimental studies showed 
that the good effects of cinacalcet on bone metabolism and vascular calcification.

Meanwhile, some limitations should be noticed in this meta-analysis: First, there was a significant heterogeneity. Selection criteria for different patients and control treatment options are possible explanations for heterogeneity. Second, language can also produce a bias. Specifically, we only choose English or exclude other qualified research. Third, several studies of small sample sizes, may reduce the statistical power. Finally, our results were based on unadjusted assessment of RRs, which might influence the results. Based on these limitations, the results should be considered carefully.

\section{Conclusion}

In conclusion, despite the limitations of this meta-analysis, our study confirmed that patients who received calcimimetic agents had significantly decreased serum PTH, calcium and calcium phosphorus product compared with patients who received control treatment. However, there was no significant difference in all-cause mortality and cardiovascular mortality between calcimimetics agents and control treatment group. Further studies with larger data set and welldesigned models are required to validate our findings.

\section{Abbreviation}

ACM: All-cause mortality; CaSR: Calcium-sensing receptor; Cl: Confidence interval; CKD: Chronic kidney disease; CV: Cardiovascular; CVM: Cardiovascular mortality; ESRD: End-stage renal disease; iPTH: Intact PTH; MBD: Mineral and bone disorder; MD: Mean difference; PTH: Parathyroid hormone; RR: Relative risk; SHPT: Secondary hyperparathyroidism

\section{Acknowledgements}

None.

\section{Authors' contributions}

YT S and BY T carried out the studies, participated in collecting data, and drafted the manuscript. ZT S and PZ W performed the statistical analysis and participated in its design. TH X and $L Y$ helped to draft the manuscript. All authors read and approved the final manuscript.

\section{Funding}

This work was supported by a grant from the National Natural Science Foundation of China (Grant No. 81770766), the National Key Research and Development Program of China (No. 2016YFC0901501), the Key Social Development Program of Science and Technology Commission of Shenyang of China (Grant No. F16-206-9-04), the Key Social Development Program of Science and Technology Commission of Liaoning Province of China (Grant No. 20170540999). These organizations had no role in study design, data collection, analysis, or interpretation of data.

\section{Availability of data and materials}

The datasets used and/or analyzed during the current study are available from the corresponding author on reasonable request.

\section{Ethics approval and consent to participate}

Not applicable.

\section{Consent for publication}

Not applicable.

\section{Competing interests}

The authors declare that they have no conflict of interest.

\section{Author details}

'Department of Clinical Medicine, China Medical University, Shenyang 110122, Liaoning, China. '2Department of Nephrology, the First Hospital of China Medical University, Shenyang 110001, Liaoning, China.

Received: 28 February 2019 Accepted: 22 November 2019

Published online: 31 July 2020

\section{References}

1. Foley RN, Murray AM, Li S, Herzog CA, McBean AM, Eggers PW, et al. Chronic kidney disease and the risk for cardiovascular disease, renal replacement, and death in the United States Medicare population, 1998 to 1999. J Am Soc Nephrol. 2005;16(2):489-95.

2. Coburn JW. An update on vitamin D as related to nephrology practice: 2003, Kidney. Int Suppl. 2003;(87):S125-30.

3. Brown EM, Gamba G, Riccardi D, Lombardi M, Butters R, Kifor O, et al. Cloning and characterization of an extracellular $\mathrm{Ca}(2+)$-sensing receptor from bovine parathyroid. Nature. 1993;366(6455):575-80.

4. Block GA, Martin KJ, de Francisco AL, Turner SA, Avram MM, Suranyi MG, et al. Cinacalcet for secondary hyperparathyroidism in patients receiving hemodialysis. N Engl J Med. 2004;350(15):1516-25.

5. Nemeth EF, Heaton WH, Miller M, Fox J, Balandrin MF, Van Wagenen BC, et al. Pharmacodynamics of the type II calcimimetic compound cinacalcet HCl. J Pharmacol Exp Ther. 2004;308(2):627-35.

6. Goodman WG, Frazao JM, Goodkin DA, Turner SA, Liu W, Coburn JW. A calcimimetic agent lowers plasma parathyroid hormone levels in patients with secondary hyperparathyroidism. Kidney Int. 2000;58(1):436-45.

7. Goodman WG, Hladik GA, Turner SA, Blaisdell PW, Goodkin DA, Liu W, et al. The Calcimimetic agent AMG 073 lowers plasma parathyroid hormone levels in hemodialysis patients with secondary hyperparathyroidism. J Am Soc Nephrol. 2002;13(4):1017-24.

8. Lindberg JS, Moe SM, Goodman WG, Coburn JW, Sprague SM, Liu W, et al. The calcimimetic AMG 073 reduces parathyroid hormone and calcium $\mathrm{x}$ phosphorus in secondary hyperparathyroidism. Kidney Int. 2003;63(1):248-54.

9. Quarles LD, Sherrard DJ, Adler S, Rosansky SJ, McCary LC, Liu W, et al. The calcimimetic AMG 073 as a potential treatment for secondary hyperparathyroidism of end-stage renal disease. J Am Soc Nephrol. 2003; 14(3):575-83.

10. Charytan C, Coburn JW, Chonchol M, Herman J, Lien YH, Liu W, et al. Cinacalcet hydrochloride is an effective treatment for secondary hyperparathyroidism in patients with CKD not receiving dialysis. Am J Kidney Dis. 2005;46(1):58-67.

11. Lindberg JS, Culleton B, Wong G, Borah MF, Clark RV, Shapiro WB, et al. Cinacalcet $\mathrm{HCl}$, an oral calcimimetic agent for the treatment of secondary hyperparathyroidism in hemodialysis and peritoneal dialysis: a randomized, double-blind, multicenter study. J Am Soc Nephrol. 2005;16(3):800-7.

12. Akiba T, Akizawa T, Tsukamoto Y, Uchida E, Iwasaki M, Koshikawa S. Dose determination of cinacalcet hydrochloride in Japanese hemodialysis patients with secondary hyperparathyroidism. Ther Apher Dial. 2008;12(2):117-25.

13. Fishbane S, Shapiro WB, Corry DB, Vicks SL, Roppolo M, Rappaport K, et al. Cinacalcet $\mathrm{HCl}$ and concurrent low-dose vitamin D improves treatment of secondary hyperparathyroidism in dialysis patients compared with vitamin $D$ alone: the ACHIEVE study results. Clin J Am Soc Nephrol. 2008;3(6):1718-25.

14. Fukagawa M, Yumita S, Akizawa T, Uchida E, Tsukamoto $Y$, Iwasaki M, et al. Cinacalcet (KRN1493) effectively decreases the serum intact PTH level with favorable control of the serum phosphorus and calcium levels in Japanese dialysis patients. Nephrol Dial Transplant. 2008;23(1):328-35.

15. Messa P, Macario F, Yagoob M, Bouman K, Braun J, von Albertini B, et al. The OPTIMA study: assessing a new cinacalcet (Sensipar/Mimpara) treatment algorithm for secondary hyperparathyroidism. Clin J Am Soc Nephrol. 2008;3(1):36-45.

16. Chonchol M, Locatelli F, Abboud HE, Charytan C, de Francisco AL, Jolly S, et al. A randomized, double-blind, placebo-controlled study to assess the efficacy and safety of cinacalcet $\mathrm{HCl}$ in participants with CKD not receiving dialysis. Am J Kidney Dis. 2009;53(2):197-207.

17. El-Shafey EM, Alsahow AE, Alsaran K, Sabry AA, Atia M. Cinacalcet hydrochloride therapy for secondary hyperparathyroidism in hemodialysis patients. Ther Apher Dial. 2011;15(6):547-55.

18. Raggi P, Chertow GM, Torres PU, Csiky B, Naso A, Nossuli K, et al. The ADVANCE study: a randomized study to evaluate the effects of cinacalcet 
plus low-dose vitamin D on vascular calcification in patients on hemodialysis. Nephrol Dial Transplant. 2011;26(4):1327-39.

19. Chertow GM, Block GA, Correa-Rotter R, Drueke TB, Floege J, Goodman WG, et al. Effect of cinacalcet on cardiovascular disease in patients undergoing dialysis. N Engl J Med. 2012;367(26):2482-94.

20. Ketteler M, Martin KJ, Wolf M, Amdahl M, Cozzolino M, Goldsmith D, et al. Paricalcitol versus cinacalcet plus low-dose vitamin $\mathrm{D}$ therapy for the treatment of secondary hyperparathyroidism in patients receiving haemodialysis: results of the IMPACT SHPT study. Nephrol Dial Transplant. 2012;27(8):3270-8.

21. Kim HJ, Kim H, Shin N, Na KY, Kim YL, Kim D, et al. Cinacalcet lowering of serum fibroblast growth factor-23 concentration may be independent from serum $\mathrm{Ca}, \mathrm{P}, \mathrm{PTH}$ and dose of active vitamin D in peritoneal dialysis patients: a randomized controlled study. BMC Nephrol. 2013;14:112.

22. Urena-Torres P, Bridges I, Christiano C, Cournoyer SH, Cooper K, Farouk M, et al. Efficacy of cinacalcet with low-dose vitamin $D$ in incident haemodialysis subjects with secondary hyperparathyroidism. Nephrol Dial Transplant. 2013;28(5):1241-54.

23. Bell G, Huang S, Martin KJ, Block GA. A randomized, double-blind, phase 2 study evaluating the safety and efficacy of AMG 416 for the treatment of secondary hyperparathyroidism in hemodialysis patients. Curr Med Res Opin. 2015:31(5):943-52.

24. Wetmore JB, Gurevich K, Sprague S, Da Roza G, Buerkert J, Reiner M, et al. A randomized trial of Cinacalcet versus vitamin $D$ analogs as Monotherapy in secondary hyperparathyroidism (PARADIGM). Clin J Am Soc Nephrol. 2015; 10(6):1031-40.

25. Mei C, Chen N, Ding X, Yu X, Wang L, Qian J, et al. Efficacy and safety of Cinacalcet on secondary hyperparathyroidism in Chinese chronic kidney disease patients receiving hemodialysis. Hemodial Int. 2016;20(4):589-600.

26. Moher D, Liberati A, Tetzlaff J, Altman DG. Preferred reporting items for systematic reviews and meta-analyses: the PRISMA statement. PLoS Med. 2009;6(7):e1000097.

27. Higgins JP, Altman DG, Gotzsche PC, Juni P, Moher D, Oxman AD, et al. The Cochrane Collaboration's tool for assessing risk of bias in randomised trials. Bmj. 2011;343:d5928.

28. Palmer SC, Nistor I, Craig JC, Pellegrini F, Messa P, Tonelli M, et al. Cinacalcet in patients with chronic kidney disease: a cumulative meta-analysis of randomized controlled trials. PLoS Med. 2013;10(4):e1001436.

29. Sekercioglu N, Busse JW, Sekercioglu MF, Agarwal A, Shaikh S, Lopes LC, et al. Cinacalcet versus standard treatment for chronic kidney disease: a systematic review and meta-analysis. Ren Fail. 2016;38(6):857-74.

\section{Publisher's Note}

Springer Nature remains neutral with regard to jurisdictional claims in published maps and institutional affiliations.

Ready to submit your research? Choose BMC and benefit from:

- fast, convenient online submission

- thorough peer review by experienced researchers in your field

- rapid publication on acceptance

- support for research data, including large and complex data types

- gold Open Access which fosters wider collaboration and increased citations

- maximum visibility for your research: over $100 \mathrm{M}$ website views per year

At $\mathrm{BMC}$, research is always in progress.

Learn more biomedcentral.com/submissions 